\title{
Permanent Fault Identification Method for Single-Phasea Adaptive Reclosure of UHVAC Transmission Line
}

\author{
Duanqiang $\mathrm{Du}^{1}{ }^{*}$, Chunming $\mathrm{Li}^{2}$, Jinwei Zhang1 \\ ${ }^{1}$ College of Electrical Power, Inner Mongolia University of Technology, Huhhot, China \\ ${ }^{2}$ College of Information Engineering, Inner Mongolia University of Technology, Huhhot, China \\ Email: ^1137973090@qq.com,chunming@imut.edu.cn,1308639349@qq.com
}

How to cite this paper: Du, D.Q., Li, C.M. and Zhang, J.W. (2017) Permanent Fault Identification Method for Single-Phasea Adaptive Reclosure of UHVAC Transmission Line. Energy and Power Engineering, 9, 149-154.

https://doi.org/10.4236/epe.2017.94B018

Received: December 17, 2016

Accepted: March 30, 2017

Published: April 6, 2017

\begin{abstract}
In order to avoid the UHVAC (Ultra High Voltage Alternating Current) transmission line with shunt reactor fault voltage smaller problems, through the analysis of single-phase permanent fault when tripping phase terminal voltage characteristics, this paper presents a fault phase voltage signal of the two order derivative and the original signal ratio of a new method for steadystate frequency discrimination single-phase permanent fault. The principle of this method is simple, and it can avoid the problem that the fault voltage caused by the installation of shunt reactor is small. The adaptability and correctness of the proposed method are verified by a large number of simulations.
\end{abstract}

\section{Keywords}

Adaptive Reclosure, Permanent Fault, Steady State Component Frequency

\section{Introduction}

Most faults in UHVAC transmission system are single phase transient fault [1]. In the traditional automatic re-lock, if the coincidence of permanent fault, the system will cause the two shock, and even make the system crash. In 1980s, Professor Ge Yaozhong put forward the idea of "adaptive reclosure" [2] arousing wide attention of experts and scholars in electrical engineering from domestic and foreign. A wealth of achievements have been made in the study of the two arc characteristics [3], the voltage characteristics [4] [5], the current characteristics of shunt reactor [6] [7] [8] and the characteristic of model parameters [9] [10]. The practical application is difficult since neural network based on the need to train a large number of samples [11] [12]. The criterion based on arc criterion 
and voltage is difficult to realize since the shunt reactor technology is widely used in the super high voltage, which accelerates the arc quenching process and limits the amplitude of the fault voltage [13].

Based on the analysis of the characteristic of single-phase permanent fault phase voltage after tripping, this paper proposes method for distinguishing single phase permanent fault based on steady-state component frequency acquired through two order derivative of the fault phase voltage signal and the ratio of the original signal.

\section{Analysis on the Characteristics of Fault Phase Voltage during Single-Phase Permanent Fault after Tripping}

During the single-phase permanent fault, fault phase voltages $U(t)$ is composed of the steady state component and the transient component, the expression was as follows:

$$
U(t)=U_{1} \sin \left(\omega_{1} t+\varphi_{1}\right)+e^{-\beta t} U_{2} \sin \left(\omega_{2} t+\varphi_{2}\right)
$$

In the formula: $U_{1}, \omega_{1}, \varphi_{1}$ represent voltage amplitude, frequency and phase steady components respectively, $U_{2}, \omega_{2}, \varphi_{2}$ represent the amplitude, frequency and phase of transient component respectively, $\beta$ is transient attenuation coefficient.

Due to the fault point to ground reliable discharge, the transient component will decay rapidly to zero, after entering the steady state, its expression is:

$$
U(t)=U_{1} \sin \left(\omega_{1} t+\varphi_{1}\right)
$$

After two order derivative of the formula (2):

$$
U^{\prime \prime}(t)=-\omega_{1}^{2} U_{1} \sin \left(\omega_{1} t+\varphi_{1}\right)
$$

and then

$$
\omega^{2}=-U^{\prime \prime}(t) / U(t)
$$

So the steady state component frequency $f$ is:

$$
f=\sqrt{U^{\prime \prime}(t) / U(t)} /(2 \pi)
$$

Because the steady state component is mainly determined by the sound phase capacitance coupling voltage and the electromagnetic coupling voltage [14], the steady state frequency $f$ is close to the frequency of the power frequency $f_{0}$. Based on the above analysis, the relations between steady state component frequency and frequency as following:

$$
f \leq k \cdot f_{0}
$$

In the formula, $k$ represents reliability coefficient. After a lot of simulation, the author found that the 1.3 is suitable in considering the line model equivalence and simplification of the simulation software, actual gap between $\mathrm{f}$ and $f_{0}$.

\section{Discriminant Principle}

In the sine function, the data in the $1 / 4$ continuous period can reflect the data of 
the whole cycle. Two arc durations are about 200 ms during transient fault [15]. Considering the above two aspects, this paper focuses on $200 \mathrm{~ms}$ time period after trip and calculates the data from power system, if calculate data in $1 / 4$ continuous power frequency period satisfied formula of (5), the fault is determined as a permanent fault. Otherwise, it will be judged as instantaneous fault. Criteria flow chart is shown in Figure 1.

\section{Simulation Results and Analysis}

As shown in Figure 2, the simulation model is based on the model of $1000 \mathrm{KV}$ UHV line system in the southeast Nanyang. Line length is $358 \mathrm{~km}$. Parameters of this line are as following:

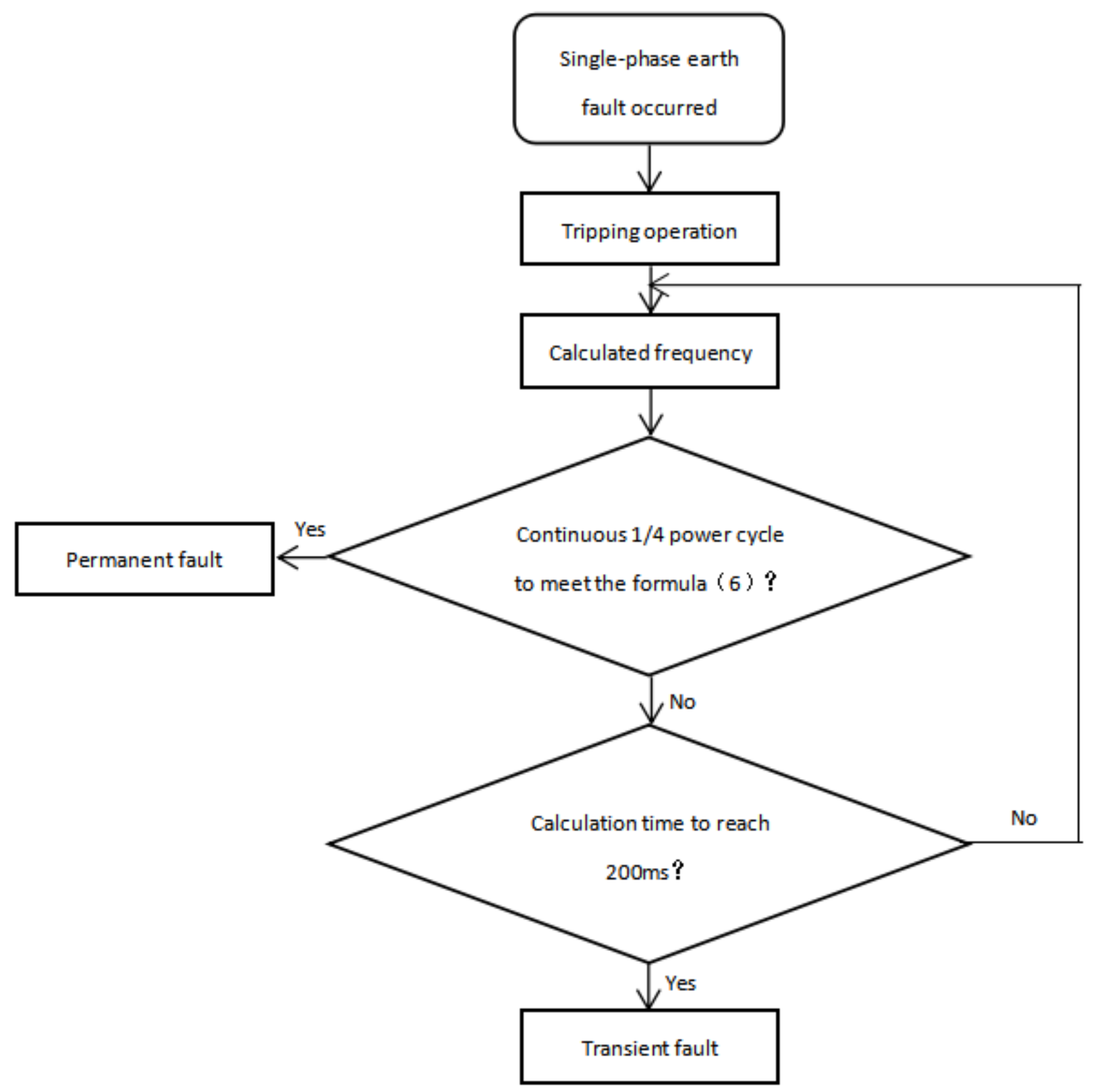

Figure 1. Criterion flow chart. 


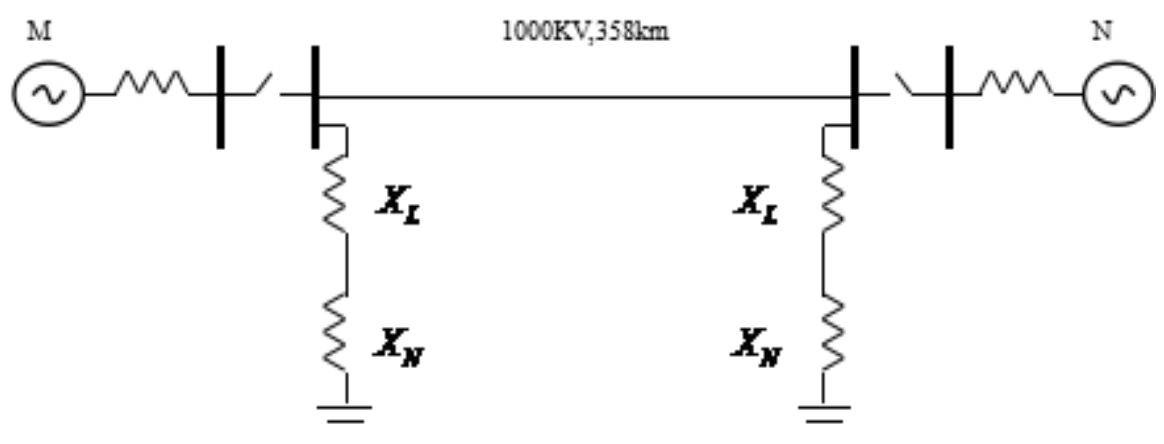

Figure 2. Model of $1000 \mathrm{KV}$ UHV transmission line system in Southeast Nanyang.

$$
\begin{aligned}
& R_{1}=0.00758 \Omega / \mathrm{km}, \quad R_{0}=0.15421 \Omega / \mathrm{km}, \quad L_{1}=0.2635 \Omega / \mathrm{km} \\
& L_{0}=0.8306 \Omega / \mathrm{km}, \quad C_{1}=0.013970 \mu \mathrm{F} / \mathrm{km}, \quad C_{0}=0.0 .009296 \mu \mathrm{F} / \mathrm{km}
\end{aligned}
$$

System parameters at both ends are:

$Z_{0 m}=0.86+j 52.74, Z_{1 m}=0.8+j 10.89, Z_{0 n}=5.69+j 14.18$, $Z_{1 n}=3.15+j 8.15$.

Parameters of shunt reactor:

$$
X_{L}=1680 \Omega / \mathrm{km}
$$

Parameters of neutral point small reactor:

$$
X_{N}=442.21 \Omega \text {. }
$$

Permanent single-phase grounding fault occurs of system in $0.5 \mathrm{~s}$, tripping in $0.1 \mathrm{~s}$, and the sampling frequency is $10 \mathrm{kHz}$. The calculation results show that the power angular phase difference are $0^{\circ}, 10^{\circ}, 20^{\circ}, 30^{\circ}, 40^{\circ}, 50^{\circ}$ respectively, the transition resistances are corresponding to $0 \Omega, 50 \Omega, 100 \Omega, 200 \Omega, 400 \Omega$, the fault distance is the line (from the $M$ side) $0 \%, 25 \%, 50 \%, 75 \%, 100 \%$ corresponding to a total of 150 cases can be accurately identified.

Table 1 and Table 2 are discriminant success time when $\theta=10^{\circ}, R=100 \Omega$.

From Table 1 we can make conclusion that when the power angle difference and transition resistance are constant, discriminant success time showing such a regularity that increase first and then decrease with increasing of $L$. When the power angle difference and the fault location is certain, discriminant success time shows decreasing trend with increasing of $R$. From Table 2 we can also seen that when the fault position and the transition resistance are at a certain time, discriminant success time showing such a regularity that increase first and then decrease with increasing of $\theta$.

By a lot of simulation data can be seen that in the UHV AC transmission system in the occurrence of a permanent fault occurs, the duration of transient component is $180 \mathrm{~ms}-55 \mathrm{~ms}$ after tripping.

\section{Conclusions}

In this paper, based on the analysis of fault phase voltage characteristics of single-phase permanent fault, this paper presents a method to determine the frequency of steady state component based on the ratio of the two derivative of the 
Table 1. Criterion flow chart successful time table when $\theta=10^{\circ}$.

\begin{tabular}{cccccc}
\hline$L$ & $0 \%$ & $25 \%$ & $50 \%$ & $75 \%$ & $100 \%$ \\
\hline$R=0 \Omega$ & 0.2435 & 0.2361 & 0.2840 & 0.2625 & 0.2729 \\
$R=50 \Omega$ & 0.2264 & 0.2256 & 0.2849 & 0.2143 & 0.2226 \\
$R=100 \Omega$ & 0.2089 & 0.2161 & 0.2860 & 0.1942 & 0.2029 \\
$R=200 \Omega$ & 0.2001 & 0.1974 & 0.2856 & 0.1824 & 0.1945 \\
$R=400 \Omega$ & 0.1724 & 0.1884 & 0.2768 & 0.1738 & 0.1840 \\
\hline
\end{tabular}

Table 2. Successful time table when $R=100 \Omega$.

\begin{tabular}{cccccc}
\hline$L$ & $0 \%$ & $25 \%$ & $50 \%$ & $75 \%$ & $100 \%$ \\
\hline$\theta=0^{\circ}$ & 0.2002 & 0.2091 & 0.2501 & 0.2084 & 0.2183 \\
$\theta=10^{\circ}$ & 0.2089 & 0.2161 & 0.2860 & 0.1942 & 0.2029 \\
$\theta=20^{\circ}$ & 0.2393 & 0.2034 & 0.2748 & 0.1821 & 0.1923 \\
$\theta=30^{\circ}$ & 0.2191 & 0.2032 & 0.2635 & 0.1823 & 0.1726 \\
$\theta=40^{\circ}$ & 0.2089 & 0.2021 & 0.2522 & 0.1815 & 0.1912 \\
$\theta=50^{\circ}$ & 0.2071 & 0.2013 & 0.2220 & 0.1812 & 0.1906 \\
\hline
\end{tabular}

fault phase voltage and the ratio of the fault phase. The method is simple, high reliability and strong adaptability, and a lot of simulation results verify that the proposed criterion is also suitable for $500 \mathrm{kV}$ ultra high voltage transmission line.

The deficiency of this criterion is that:

1) Although this criterion can accurately identify the fault, the discriminant success time affected by transition resistance relatively large; 2) Due to the use of the ratio method, the denominator (fault phase voltage) may be zero, but not appear in the simulation.

\section{References}

[1] Bai, X. andZheng, W.J. andLi, G.Q.(2015) Study on Electromagnetic Transient Problem under Asymmertric Faults of EHV/UHV. Power Technology,139,1751-1751.

[2] Ge, Y.Z.(1984) Method of distinguishing between instant and permanent faults during automatic. Journal of Xi'AnJiaoTong University, 18,23-31. https://doi.org/10.1016/j.epsr.2006.04.006

[3] Elkalashy, N.I. and Darwish, H.A. and Taalab, A.I. (2007) An Adaptive Single Pole Autoreclosure Based on Zero Sequence Power.Electric Power Systems Research,77,438-446.

[4] Wang, Z.P. andLiu, H.F. andXu, Y. (2006) Criterion for Determining Fault Nature in Adaptive Single-Phase Reclosing for Shunt Compensated EHV/UHV Transmission lines. Power System Technology, 30, 29-34.

[5] Li, B.T. and Li, Y.L.(2009) A New Criterion for Adaptive Single Pole Auto-Reclosureof Ehv Transmission Lines with Shunt Reactor Compensation. Automation of Electric Power Systems, 33,48-54.

[6] Suo, N.J.L., Sun, D.D. andFu, W. (2006) Identification of Permanent Faults for Single-Phase Auto-Reclosureon Transmission Lines with Shunt Reactors. Proceeding of 
the CSEE,26,75-81.

[7] Shang, L.Q. andBai, W.Z. and Cheng G. (2008) Fault Nature Identification for Single-Phase Adaptive Reclosureon Transmission Lines with Shunt Reators. Automation of Electric Power Systems, 32,81-84.

[8] Suo, N.J.L. and Song, G.B. and Shao, W.Q. (2007) Identification of Permanent Faults Based on Differential Current Protection for Transmission Lines with Two Shunt Reactors. Automation of Electric Power Systems,31,56-60.

[9] Suo, N.J.L. and Shao, W.Q. andSong, G.B. (2009) Study on Single-Phase Adaptive Reclosure Scheme Based on Parameter Identification. Proceeding of the CSEE, 29,48-54.

[10] Suo, N.J.L. andJia, M.L.H. andSong, G.B.(2008) Permanent Fault Identification Method Based on Capacitance Parameter.Journal of Xi'AnJiaoTong University, 42,708-712.

[11] Nie, H.Z.,Dong, S. and Li, T.Y., et al. (2005) Single-phase Adaptive Auto-Reclosure Based on Fuzzy Neural Network. Power System Technology, 29,75-79.

[12] Yang, W., Peng, L. and Zhang, J.F. (2005) ADapativeautoreclosure of Single Phase Based on FNN. Relay, 33,66-70.

[13] Wang Q.Q., Wang H.F. and Lin, D. (2015) An Identification Method of Single-Phase Permanent Fault at Transmission Lines with Shunt Reators. Automation of Electric Power Systems,39,101-106.

[14] Shao, W.Q., Zhang, X.W. and Song, J.X.(2013) Non-fault Identification Voltage and Current Based Integrated Criterion for Single-Phase Reclosure on UHVACtransmissionLines. High Voltage Engineering, 39,546-554.

[15] Xin, L., Zhao, D.D. and Cao, L. (2016) Study on the Induced Voltage And Potential Current of UHVAC Transmission Project. Electrical Technology,2,42-46.

[16] Cheng, L., and Song, Z.L. (2010) An Approach to Identify Faults in UHV AC Transmission Line Equipped with Shunt Reactor. Power System Technology,34,216-222.

Submit or recommend next manuscript to SCIRP and we will provide best service for you:

Accepting pre-submission inquiries through Email, Facebook, LinkedIn, Twitter, etc. A wide selection of journals (inclusive of 9 subjects, more than 200 journals)

Providing 24-hour high-quality service

User-friendly online submission system

Fair and swift peer-review system

Efficient typesetting and proofreading procedure

Display of the result of downloads and visits, as well as the number of cited articles

Maximum dissemination of your research work

Submit your manuscript at: http://papersubmission.scirp.org/

Or contact epe@scirp.org 